\title{
New-generation combined oral contraceptives linked to raised risk of thrombosis
}

The association between use of oral contraceptives and increased risk of venous thrombosis has long been known, although lowering of the estrogen dose in combined oral contraceptive (COC) preparations from $100 \mu \mathrm{g}$ to $50 \mu \mathrm{g}$ has reduced the level of risk. Many modern COCs now contain doses of

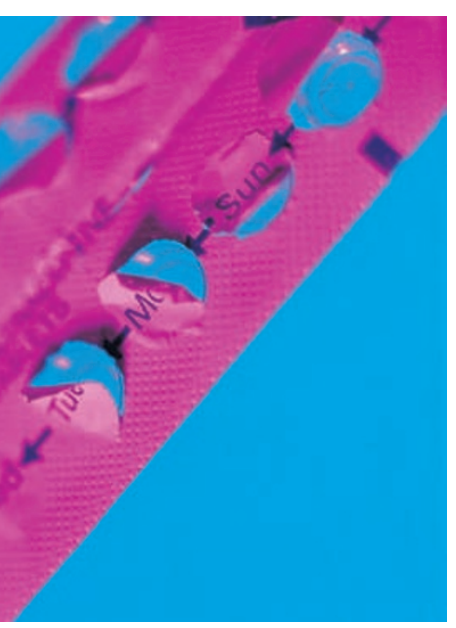

estrogen below even $50 \mu \mathrm{g}$. Furthermore, many new-generation COCs contain drospirenone rather than levonorgestrel (the progestogen most commonly used in the previous generation of COCs), but conflicting data exist as to whether this new progestogen is as safe as its predecessors. Two European studies have recently demonstrated that COCs that contain levonorgestrel and a low dose of estrogen are safer than new COCs that contain drospirenone.

Frits Rosendaal, lead investigator of the MEGA case-control study (performed in The Netherlands) says that this research "was needed because 100 million women worldwide use oral contraceptives, [and these women] are young and healthy, so we have to make completely sure they use the safest [formulation]."

In both the MEGA study and a cohort study conducted by Lidegaard and colleagues using Danish national registry data, estrogen dose (ranging from $20 \mu \mathrm{g}$ to $50 \mu \mathrm{g}$ ) was positively associated with risk of venous thrombosis for the COCs analyzed. Additionally, compared with COCs containing levonorgestrel, those containing the progestogens gestodene, desogestrel, cyproterone acetate or drospirenone were associated with an increased risk of thrombosis. Both studies also found that risk of venous thrombosis decreased with increased duration of use.

According to Øjvind Lidegaard, "women at an increased risk of venous thrombosis who, despite this risk, ask for COCs, should be prescribed COCs with levonorgestrel or should shift to a progestogen-only product."

Bryony M. Mearns

Original articles Lidegaard, $\emptyset$. et al. Hormonal contraception and risk of venous thromboembolism: national follow-up study. BMJ 339, b2890 (2009). van Hylckama Vlieg, A. et al. The venous thrombotic risk of oral contraceptives, effects of oestrogen dose and progestogen type: results of the MEGA case-control study. BMJ 339, b2921 (2009). 